\title{
Grapes in School Meals: Impact of Plate Waste on Costs and Consumption
}

\author{
Peter S Murano ${ }^{1 *}$ and Oral Capps ${ }^{2}$ \\ ${ }^{1}$ Senior Associate Professor, Department of Nutrition and Food Science, Texas A\&M University, Regents Professor, Executive \\ Professor, and Co-Director of the Agribusiness, Food \& Consumer Economics Research Center
}

${ }^{2}$ Department of Agricultural Economics, Texas A\&M University

Received: November 17, 2017; Accepted: December 20, 2017; Published: January 8, 2018

*Corresponding author: Peter S. Murano, Senior Associate Professor, Department of Nutrition and Food Science, Texas A\&M University, 2253 TAMU, College Station, TX 77843-2253, Tel: 979-862-7955, Fax: 979-458-3129, E-mail: psmurano@tamu.edu

\begin{abstract}
Objectives: To examine Plate Waste (PW) from elementary and middle school-aged children by school and by grade when grapes were on the lunch menu versus when they were absent. The primary hypothesis tested was that grapes enhance consumption and lessen plate waste, thereby serving as a "gateway" fruit to healthier eating. The foods examined were selected fruits, vegetables, and entrées. The endpoints of analysis included lost dollars and lost nutrients (calories, fat, sodium, protein, and fiber).
\end{abstract}

Methods: In two elementary schools and two middle schools from one school district (ISD) in Texas, PW of food items served on the school lunch menu was calculated for all students collectively by grade, enabling comparisons between the two school levels.

Results: Findings suggest that when the food environment included grapes, consumption of healthier menu items increased, while consumption of less healthy menu items decreased. On grape days, lost dollars per serving of vegetables was lower compared to non-grape days. This difference was significantly different from zero. Intakes of effective calories, fat, sodium, protein, and fiber per serving of entrées, vegetables and fruits on grape days were higher versus non-grape days, and differences were statistically significant.

Conclusions: The presence of grapes had a positive impact regarding the school lunch eating behaviors of children. PW of entrée, fruit, and vegetable items impacted nutrient consumption as well as wasted dollars -considerations for school foodservice.

Key words: Healthy Hunger-Free Kids Act (HHFKA), National School Lunch Program (NSLP), plate waste, grapes, lost dollars, effective nutrient.

\section{Introduction}

The Food and Nutrition Service (FNS) of the United States Department of Agriculture (USDA) administers school meals programs across the nation through its Child Nutrition Division. Regulations for the Child Nutrition Programs require, for instance, that each reimbursable breakfast or lunch served contain vegetables and/or fruits. Vegetables and fruits also may be served as part of reimbursable snacks for the National School Lunch, Child and Adult Care Food, or Summer Food Service
Programs. Two or more servings of different vegetables and/or fruits must be served to meet the vegetable/fruit requirement. Grapes are a popular fruit among school children, and $1 / 4$ cup raw grapes (approximately seven large grapes or fourteen grape halves) constitute a meal contribution serving size.

In January of 2013, USDA published a proposed rule to update the nutrition standards for meals served through the National School Lunch and School Breakfast programs as part of the Healthy, Hunger-Free Kids Act (HHFKA) of 2010. The proposed rule created the first major improvement in the nutritional quality of school meals in fifteen years, and the proposed rule was an essential step in addressing the challenge of childhood obesity within a generation. The change in standards resulted in increased fruit and vegetable offerings provided at lunch and for the first time, both fruits and vegetables were served daily. Amid concerns that a revised and restrictive school meals menu might create unintended consequences such as greater food waste, school-based research studies have begun to demonstrate that the HHFKA's supportive built environment can enhance fruit and vegetable consumption [1].

It has been suggested that certain fruits and vegetables may serve as gateway foods to promote healthier overall food consumption. For example Drewnowski, et al. reported that children whose weekday lunches included non-fried white potatoes consumed a median of 0.37 servings of other vegetables at lunch as compared to only a median of 0.19 servings for children whose lunches did not include potatoes [2]. In a recent observational study McGill, et al. examined the association of grape consumption -fresh grapes, raisins and $100 \%$ grape juice - with the diet quality of a nationally representative sample of U.S. children and adults [3]. Their findings suggest that, among adults and children, consumption of grapes and grape products is associated with healthier dietary patterns and improved nutrient intakes.

McGill, et al. analyzed the diets of more than 21,800 children and adults using data from the 2003-2008 National Health 
and Nutrition Examination Survey (NHANES) and found that consumers of grapes and grape products had increased intakes of total and whole fruit as well as vitamin A, vitamin C, vitamin B6, dietary fiber, calcium, magnesium, and potassium versus nonconsumers of grapes and grape products [3]. Dietary fiber, calcium and potassium are especially important, as most Americans are currently not getting enough of these essential nutrients in their daily diets. Not only were healthier food options increasingly consumed, but in addition, less healthy food consumption decreased. Adult grape and grape product consumers had increased intakes of vegetables, whole grains, nuts and seeds but lower intakes of added sugars, total fat, saturated fat and cholesterol compared to non-consumers.

In order to achieve increased fruit and vegetable consumption, we hypothesize that when the food environment includes grapes, consumption of healthier menu items increase, while consumption of less healthy menu items decrease. These outcomes also may be influenced by various factors, including the ages of the children, class level (grades $\mathrm{K}$ through 8), and school level (elementary, middle). At the elementary school level, children are typically first offered fruit in a cafeteria setting, including whole grapes, as part of school meals. Fruit may be in one of several forms, including fresh, canned, and dried. At the middle school level, patterns of consumption/waste presumably may have already been established, which our study sought to understand.

\section{The objectives of this research are as follows:}

- To investigate the relationship of the consumption/waste of fruits, vegetables, and entrees when grapes are present versus absent from the school lunch meal.

- To determine overall nutritional and cost differences due to the presence/absence of grapes in selected elementary and middle schools and

- To examine the impacts of school level and grade level in consumption and waste associated with school lunches.

\section{Methods}

\section{Schools}

This study was conducted in two elementary schools and two middle schools from a particular Independent School District (ISD) located in central-east Texas. The respective schools were diverse in terms of eligibility for free/reduced-price school meals, providing a representative sample. The research did not involve any personal identifiers of the participants. The study was approved as exempt by the Institutional Review Board (IRB) at Texas A\&M University, IRB study \# IRB2014-0647.

Upon approval from the superintendent, principals and the nutrition services personnel, researchers were permitted access to the schools for the purpose of data collection on days that each school determined were most feasible. Researchers did not control food menu decisions or select or otherwise influence the specific children participating on collection days. The plate waste was collected in fall of 2014 via two visits to each school, encompassing six elementary grades (K-5) and three middle school (grades 6-8). Four collections (two grape and two nongrape collections per visit) resulted in a total of 72 observations (48 observations in the elementary schools and 24 observations in the middle schools). The number of observations was derived as follows: [six grades* four collections* two schools] for the former, and [three grades* four collections* two schools] for the latter. All the schools served multiple fruit options each day, and students had the choice to select up to three servings of fruit during the lunchtime meal.

\section{Participants}

The study participants were elementary school children from kindergarten to fifth and middle school children from sixth, seventh and eighth grades who participated in the NSLP. All other students were excluded from the study. Students were required to select milk, an entrée, and at least one fruit or vegetable in order for the meal to qualify as free or reduced. Lunch periods were scheduled by grade and the amount of time allocated for lunch was 30 minutes. All students were required to remain in their seats during the entire lunch period. Menu items and servings sizes were observed for consistency throughout all lunch periods for each visit although variation naturally occurred from one serving to another. Teachers explained the plate waste collection protocol to their students and instructed the students that they were not obligated to participate. No other school-wide nutrition intervention program was be implemented during the study.

\section{Menu}

At elementary schools, a maximum of three entrees were offered, with the menu cycling through an eight-week rotation. Corresponding vegetables and fresh condiments were offered with each of the entrees as well. In addition to grapes, typically, four to five additional prepared (canned) fruits were offered, such as mixed fruit cocktail, peaches, applesauce, pineapples, and mandarin oranges. Whole fruit that was available included whole bananas, oranges, and red and green apples, in addition to grapes. Both red and green grapes were offered, based upon availability and cost. Typically fourteen grapes were offered per tray; red and green grapes were not mixed. Dried fruit specifically raisins and Craisins - were offered as a fruit choice. It was not feasible to estimate whole fruit waste of apples, oranges and bananas since these fruits would have to be collected individually. Apples, oranges, and bananas contain cores and peels that made plate waste estimates problematic within our manpower and budget limitations; therefore those fruits were excluded from calculations. Since canned fruits and vegetables are typically packed within hours of harvest, their peak flavor and nutritional value are preserved - making comparisons relevant and equivalent.

\section{Lunch Lines}

At the elementary schools, classes entered the cafeteria by grade, progressed through the lunch line by grade, then 
assembled and ate together as a grade. There was a staggered entry of grades from $\mathrm{K}$ through 5 , with each grade having about 20 minutes to complete lunch. There were up to two lunch lines in operation, each offering the same menu items. Importantly, recess always occurred after lunch.

\section{Student Flow}

As they entered the lunch line, students selected milk; the cafeteria worker next served entrées and hot legumes (baked or refried beans). Students selected cold vegetables (carrots, garden salad), condiments (cheese, jalapeños, etc.), fruit (including grapes), and snacks. Condiment packets such as ketchup, mustard, etc. could be selected as students paid for their meal. Cold vegetables, fresh condiments (salsa, jalapenos, etc.) and fruit were all served in small black trays. Students could purchase snacks with their own money, including juice boxes, water bottles, Go-Gurts, cheese sticks, cereal bars, gingerbread cookies, and Goldfish crackers. These items were excluded from our study and did not contribute to the collection of plate waste data.

\section{Grapes}

Grapes were made available at meals on "grape days" as an offered fruit choice. Either red or green grapes were offered. On grape days, other fruit was always offered in addition to the grapes being offered. Other fruits included canned peaches, pineapples, apple sauce and mandarin oranges. Non-grape days were defined as those days when grapes were not offered as a fruit option. On these days, "other fruits" were offered as previously stated. Cafeteria staff pre-served a measured volume of grapes in small black trays. On grape days, two lines of grapes were added to the lines of canned fruit in the cafeteria (often one line of pineapples, one line of mandarin oranges and one line of peaches). Fruit cocktail that contained grapes, boxed raisins, and Craisins were not included in the data collection.

\section{Study Design}

The plate waste study design was modeled after the aggregate plate waste method of $\mathrm{Chu}$, et al. [4]. Prior to the study implementation, project personnel obtained lunch menus from the schools and based on the project needs, space in the schools, and personnel as well as time and budget limitations, developed a protocol to collect plate waste for different entrées, vegetables and fruits (one of which was grapes).

Inclusions: All students who participated in the NSLP were included in the study. A variety of entrées, vegetables and fruits were included in the data collection, except for those noted as exclusions below.

Exclusions: Whole fruit (bananas, apples, oranges) were excluded due to lack of space, time and manpower to separate skin, seeds, and core. In addition, snack foods (cookies, ice cream, chips) if purchased, and food items that could not be pre-weighed (e.g. taco toppings) also were excluded from the study.

\section{Collection}

Prior to the day of collection, based on the next day's menu (collection day menu), trash bags were weighed and labeled by grade and food item and placed in bins. Each food item to be collected corresponded to a separate bin. The bins were lined with the labeled trash bags in the order of grades entering the cafeteria. On the day of the study, the researchers arrived at the schools about an hour prior to the start of lunch. At one end of the cafeteria two tables were set, one with bins to collect plate waste from children who took grapes and the other with bins to collect plate waste from students not choosing grapes. At the lunch line, 3-5 servings of all menu items of interest were pre-weighed prior to arrival of students. Measurements were recorded to the nearest 0.1 gram to obtain the average weight for one serving. Average pre-weight of three samples of every item (fruit, vegetable, entrée) were collected.

As the students entered the cafeteria and lined up at the lunch lines, two research assistants were positioned at the register to affix post-it notes (color-coded) providing information identifying which foods were on each child's tray. Upon completion of the meals, the research assistants at the preset tables collected trays from the students and separated the trays at the grape or nongrape table. Each of the leftover food was then emptied into the appropriate trash bin. The post-it note from each tray was collected in a labeled box. The other foods that were not part of the data collection (snack items, drinks, etc.) were discarded, and the used trays were returned to the cafeteria personnel. As each grade exited the cafeteria, the trash bags containing the plate waste were tied up and placed to the side. The bins were then lined with labeled trash bags for the next grade finishing their lunch. This process was repeated for every grade. At the end of all the lunch periods, the trash bags containing the aggregate waste for each menu item by grade were weighed and recorded. The trash bag collection was essential in order to determine the overall amount of each food item that was wasted.

The use of post-it notes facilitated information retrieval by the research associates. Each post-it note provided information of all the foods selected by the students as well as each child's grade and gender.

\section{Data Analysis}

Plate waste was defined as the quantity of edible portions of food served that students discarded. After each collection, researchers entered all the preliminary data into Excel spreadsheets. For each school and grade, we measured aggregate plate waste for each entrée, vegetable and fruit. Aggregate plate waste of every item was obtained by subtracting the weight of the trash bag from the aggregate plate waste with the trash bag. The percentage of plate waste for entrées, vegetables and fruits was calculated as follows:

- Aggregate plate waste for each item divided by the total number of children who selected the item) $* 100 /$ (Weight of the mean serving size for individual item) 
- Calories and nutrients consumed = (item calories or nutrients)*[(1-(percentage of plate waste/100)]

The use of percentages for plate waste serves to standardize results across entrees, vegetables, and fruits. As such, comparisons can be made by school, by grade, and by menu item.

The nutrient profile for food items of interest per serving was provided by the school district. The actual consumption of calories and specific nutrients (dietary fiber, sodium, fat, and protein), hereafter termed effective calories and effective nutrients, was calculated to determine the intake of nutrients from all items based on the percentage of plate waste. The intakes of calories and sodium, determined from plate waste, were assessed according to USDA Nutrition Standards for the NSLP specifications, while the intakes of other nutrients including average dietary fiber were assessed according to the 2009 Institute of Medicine nutrient targets [5].

In accordance to the revised USDA nutrient standard guidelines, schools served at minimum $2 \frac{1}{2}$ cups of fruit each week or $1 / 2$ cup each day making the elementary and middle schools an ideal environment (as compared to high-school students) to be studied since fruit requirements are identical allowing us to study differences between elementary and middle school students.

\section{Demographic Characteristics}

Demographic characteristics for the four participating schools (E1, E2, M1, M2 for the two elementary schools and the two middle schools, respectively) are presented in table 1 . This table

Table 1: Demographic information for enrollment at elementary and middle schools

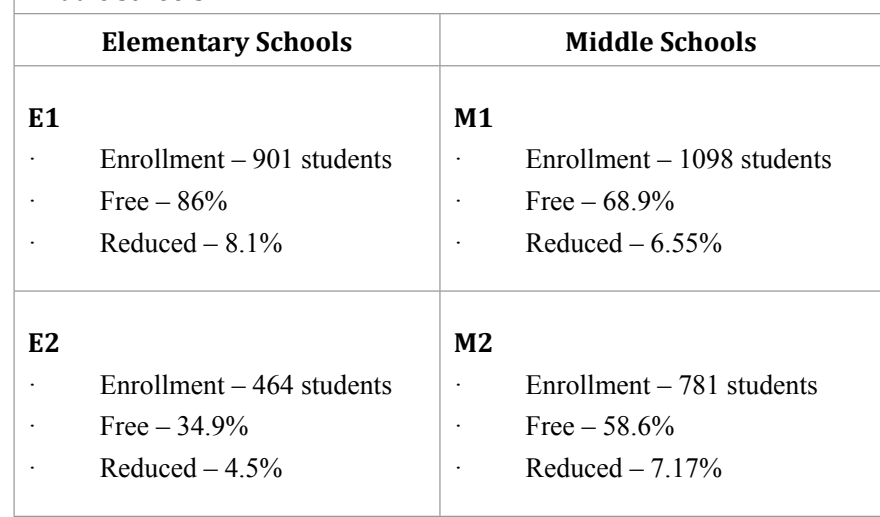

Note: This table holds demographic information regarding numbers of students enrolled in each elementary school (E1, E2) and each middle school (M1, M2) as well as the percentages of free and reduced price meal students participating at each school.

Source: Data obtained from the ISD.

details the total student enrollment per school as well as NSLP eligibility of children at the free and reduced price levels (F/RP). The student enrollment data for the four schools ranged from under 500 students (E2) to over 1,000 (M1). There was diversity also with respect to the NSLP F/RP eligibility. The ranking from greatest F/RP school children to least was E1 (96\%) > M1 (74\%) $>$ M2 (65\%) > E2 (35\%).

\section{Results}

Data pertinent to this study were analyzed using the software package EVIEWS 8.0. In particular, statistical tests were performed on mean differences in plate waste and consumption (or intakes) for all menu items of interest when grapes "were present" or "not present". The Welch F-test was chosen to test the equality of means due to the fact that this statistic takes into account unequal variances. The level of significance chosen for all statistical tests was 0.05 .

\section{Grape Plate Waste (PW)}

When compared to the waste of other fruits, grapes were wasted less. At the schools, observations and data were obtained on "grape days" when grapes as well as other fruits were served as well as on "non-grape days" (no grapes served, the other fruits still served). On average, the fruit plate waste when grapes were present was approximately 28 percent, while the PW with other fruit was approximately 33 percent. This difference in plate waste was statistically significant $(P=0.0045)$. Hence sample evidence exists to confirm that when offered as a fruit choice, grapes are minimally wasted. Although grape plate waste was lower than other fruit plate waste, both grape plate waste and other fruit plate waste was higher in elementary schools (grades K-5) compared to middle schools (grades 6-8) (Figure 1).

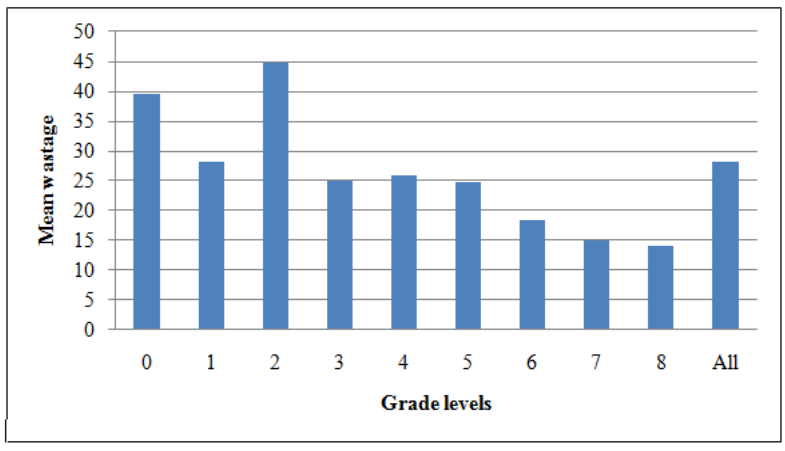

Figure 1: Plate waste of grapes by grade

Note: Plate waste of grapes was significantly higher in elementary schools (grades K-5) compared to middle schools (grades 6-8) $(P=0.0000)$. (Grade $0=\mathrm{K}$, kindergarten).

Source: Calculations by the authors using EVIEWS 8.0.

\section{Lost Dollars}

When a food item is not consumed and is discarded in the trash, this situation represents lost dollars to school foodservice. In our study, we observed a school level effect regarding lost dollars as follows (Figure 2). Lost dollars per serving of entrées, vegetables, and fruit were higher for elementary schools (grades $\mathrm{K}-5$, ranging from $\$ 0.1037$ to $\$ 0.1470$ ) in comparison to middle schools (grades 6-8, ranging from $\$ 0.0536$ to $\$ 0.0862$ ). These 


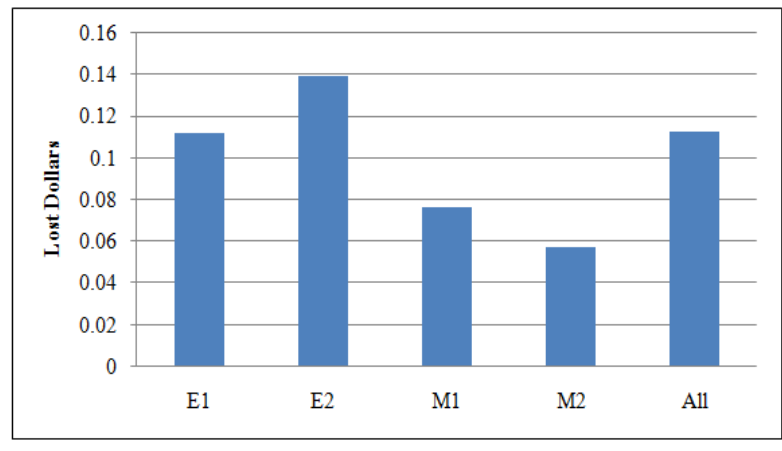

Figure 2: Average lost dollars per serving for entrees, vegetables, and fruits in elementary (E1, E2) versus middle schools (M1, M2)

Note: Lost dollars per serving of entrees, vegetables, and fruit were significantly higher for elementary schools compared to middle schools $(P=0.0000)$

Source: Calculations by the authors.

differences in lost dollars per serving by school were significantly different from zero $(\mathrm{P}=0.0000)$. In terms of percentages, lost dollars from elementary schools ranged from $25.79 \%$ to $36.54 \%$, while lost dollars from middle schools ranged from $9.37 \%$ to $14.54 \%$. We examined the impact of lost dollars in vegetable waste on grape days versus non-grape days. When grapes were offered, lost dollars attributed to plate waste for vegetables amounted to $\$ 0.0266$ per serving on average, compared to $\$ 0.0351$ when grapes were not offered. This difference was statistically significant $(p=0.0205)$.

\section{Nutrients (Calories, Fat, Sodium, Protein, and Fiber) Calories}

We examined the combined effective calories (the consumed calories calculated after accounting for plate waste) of entrées, vegetables, and fruits on grape days versus non-grape days. As exhibited in table 2, on grape days, combined effective calories from entrées, vegetables, and fruits was $113.16 \mathrm{kcal}$ per serving on average. This average decreased on non-grape days to 110.33 kcal per serving. This difference however was not statistically different from zero $(P=0.6333)$. We also examined the combined effective calories from entrées, vegetables, and fruits in elementary versus middle schools. Effective calories per serving of entrées, vegetables, and fruits were lower for elementary schools (grades K-5) in comparison to middle schools (grades 6-8). Effective calories per serving of entrées, vegetables, and fruits ranged from $79.95 \mathrm{kcal}$ to $115.72 \mathrm{kcal}$ for elementary schools and from 154.59 kcal to $160.58 \mathrm{kcal}$ for middle schools. Based on the Welch F-test, these differences in effective calories per serving by grade were significantly different at the 0.01 level.

Table 2: Effect of plate waste on calories comparing grape and non-grape days across elementary and middle schools

\begin{tabular}{|c|c|c|c|c|c|}
\hline Grapes Offered & Mean & Median & Maximum & Minimum & $\begin{array}{c}\text { Standard } \\
\text { Deviation } \\
\text { observations }\end{array}$ \\
\hline No & 110.34 & 105.04 & 231.49 & 0.03 & 50.92 \\
\hline Yes & 113.16 & 104.54 & 317.61 & 0.49 & 52.86 \\
\hline
\end{tabular}

Note: Effect of plate waste on effective calories (kcal) comparing grape and non-grape days showed no significant differences $(P=0.6333)$.

Source: Calculations by the authors using EVIEWS 8.0.

Fat

Typically, the amount of fat in fruit is quite low. We observed that the effective fat (which refers to the consumed fat grams calculated after accounting plate waste)for fruit amounted to 0.31 g per serving on average when grapes were offered and 0.09 g per serving on average on non-grape days. This difference was statistically significant $(P=0.0000)$.When we examined effective fat per serving fromen trees, vegetables, and fruit, elementary schools wasted significantly more fat from these components than did middle schools. The specific entrées that experienced the most waste on grape days were cheese enchiladas (18.08 g per serving), chicken nuggets (14.60 g per serving), chili cheese hot dog (12.48 g per serving), and breaded chicken sandwich (12.43 g per serving) (Figure 3). Effective fat per serving from entrées was lowest for cheesy potatoes (1.81 g per serving), BBQ on a bun (6.28 g per serving), and hamburgers ( 7.88 g per serving).

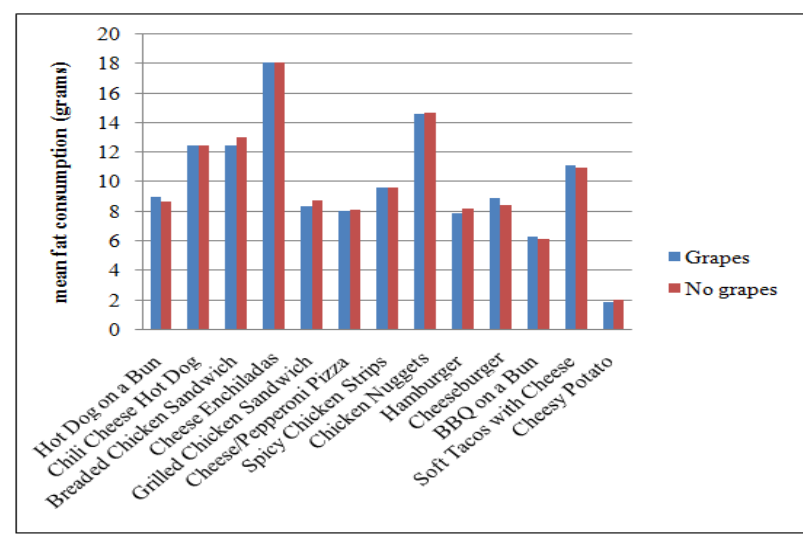

Figure 3: Effective fat per serving fromen trees on grape days versus non-grape days

Note: No statistically significant differences in effective fat per serving from entrees on grape days versus non-grape days were evident. Source: Calculations by the authors using EVIEWS 8.0. 
By comparison, on non-grape days, effective fat per serving from entrées were highest for cheese enchiladas (18.08 g per serving), chicken nuggets (14.71 g per serving), breaded chicken sandwich (13.05 g per serving), and chili cheese hot dog (12.48 g per serving). In addition, effective fat per serving of entrées were lowest for cheesy potatoes (1.99 g per serving), BBQ on a bun (6.08 g per serving), cheese/pepperoni pizza (8.07 g per serving), and hamburgers (8.14 g per serving). No statistically significant differences in effective fat per serving from specific entrees on grape days versus non-grape days were evident.

Effective fat per serving from entrées, vegetables, and fruit was lower for elementary schools in comparison to middle schools. Effective fat per serving of entrées, vegetables, and fruit for the elementary schools ranged from $2.71 \mathrm{~g}$ to $4.43 \mathrm{~g}$, while effective fat per serving of entrees, vegetables, and fruit for the middle schools ranged from5.39 $\mathrm{g}$ to $6.05 \mathrm{~g}$. These differences in effective fat per serving by school were significantly different from zero $(P=0.0000)$.

\section{Sodium}

The effective sodium depended largely upon the entrée component of the meal and exhibited a school level effect (Figure 4). On grape days, effective sodium per serving from entrées was highest for chili cheese hot dogs (1,036.27 mg per serving), hot dogs on a bun (654.46 mg per serving), and cheese enchiladas (602.49 mg per serving). The effective sodium per serving from entrées was lowest for cheesy potatoes (139.52 mg per serving), grilled chicken sandwiches (274.60 mg per serving), spicy chicken strips (357.49 mg per serving), and hamburgers (359.54 per serving).

On non-grape days, effective sodium per serving from entrées was highest for chili cheese hot dogs (1,035.78 mg per serving), hot dogs on a bun (630.17 mg per serving), cheese enchiladas (602.70 mg per serving), and breaded chicken sandwiches (577.46 mg per serving). The effective sodium per serving from entrées was lowest for cheesy potatoes (153.24 mg per serving), grilled chicken sandwiches (287.70 mg per serving), spicy chicken strips (356.11 mg per serving), and hamburgers (371.21 mg per serving). No statistically significant differences in effective sodium per serving from specific entrees on grape days versus non-grape days were evident.

Effective sodium per serving from entrées, vegetables, and

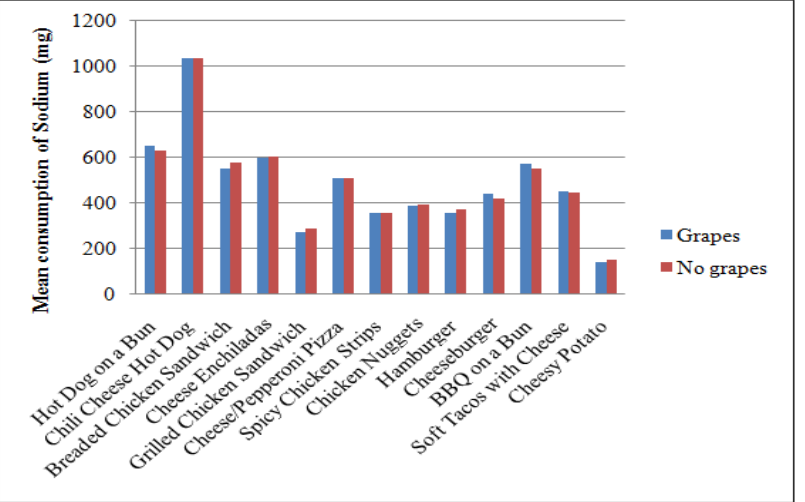

Figure 4: Effective sodium per serving from entrees by type of entrée Note: No statistically significant differences in effective sodium per serving from entrees on grape days versus non-grape days were evident.

Source: Calculations by the authors using EVIEWS 8.0.

fruits was lower for elementary schools (grades K-5), ranging from $171.92 \mathrm{mg}$ to $232.72 \mathrm{mg}$, in comparison to middle schools (grades 6-8), which ranged from $260.21 \mathrm{mg}$ to $266.81 \mathrm{mg}$. These differences in effective sodium per serving by school were significantly significant.

\section{Protein}

Similar to the situation with fat, typically, the amount of protein in fruit is quite low. We observed that the effective protein (which refers to the consumed protein grams calculated after accounting plate waste) for fruit was 0.24 g per serving on average. When grapes were not offered, effective protein attributed to plate waste for fruit amounted to $0.08 \mathrm{~g}$ per serving on average. This difference was statistically significant $(P=0.0000)$.

We also examined effective protein on grape days versus nongrape days with respect to the three meal components under analysis - fruits, vegetables, and entrées table 3 . When grapes were offered, effective protein from entrees, vegetables, and fruit amounted to $6.13 \mathrm{~g}$ per serving on average. When grapes were not offered, effective protein from entrees, vegetables, and fruit amounted to $6.08 \mathrm{~g}$ per serving on average. Although there was an increase in protein intake and a decrease in waste observed on grape days versus non-grape days, this difference was not significant $(P=0.9319)$.

Table 3: Effective protein (g) per serving from entrees, vegetables, and fruit when grapes are offered and when grapes are not offered across elementary and middle schools

\begin{tabular}{|c|c|c|c|c|c|c|}
\hline Grapes Offered & Mean & Median & Maximum & Minimum & $\begin{array}{c}\text { Standard } \\
\text { Deviation }\end{array}$ & $\begin{array}{c}\text { Number of } \\
\text { Observations }\end{array}$ \\
\hline No & 6.08 & 4.41 & 17.98 & 0.03 & 4.52 & 114 \\
\hline Yes & 6.13 & 4.99 & 18.94 & 0.49 & 4.23 & 224 \\
\hline
\end{tabular}

Note: Differences in effective protein per serving from entrees, vegetables, and fruit when grapes are offered and when grapes are not offered were not statistically different from zero $(P=0.9319)$.

Source: Calculations by the authors using EVIEWS 8.0. 
As before, we observed a school level effect in that effective protein per serving from entrées, vegetables, and fruit was lower for elementary schools (grades K-5) in comparison to middle schools (grades 6-8). Effective protein per serving from entrées, vegetables, and fruit ranged from $3.54 \mathrm{~g}$ to $5.17 \mathrm{~g}$ for elementary schools. Effective protein per serving of entrées, vegetables, and fruit ranged from $11.59 \mathrm{~g}$ to $11.95 \mathrm{~g}$ for middle schools. These differences in effective protein per serving by school were significantly different at the 0.01 level. The P-value associated with this test was 0.0000 .

\section{Fiber}

The predominant sources of fiber were the vegetables in our analysis. By comparison, the fruits, including the grapes, showed effective fiber of about half a gram (500 mg). Effective fiber for vegetables was significantly higher on non-grape days compared to grape days $(P=0.0045)$. On grape days, the effective fiber peaked with ranch style beans (3.59 g per serving) and refried beans (2.97 g per serving), while on non-grape days refried beans contributed 5.03 grams of effective fiber and 3.02 grams with baked beans. When grapes are offered, effective fiber from entrees, vegetables, and fruit amounted to $1.59 \mathrm{~g}$ per serving on average, while when grapes were not offered, effective fiber from entrees, vegetables, and fruit amounted to $1.62 \mathrm{~g}$ per serving on average. However, this difference was not statistically significant $(P=0.5896)$.

Effective fiber per serving from entrées, vegetables, and fruit was lower for elementary schools (grades $0-3$ ) in comparison to elementary schools (grade 4-5) and middle schools (grades 6-8). Effective fiber per serving of entrées, vegetables, and fruit ranged from $1.36 \mathrm{~g}$ to $1.78 \mathrm{~g}$ for elementary schools. Effective fiber per serving from entrées, vegetables, and fruit ranged from $1.65 \mathrm{~g}$ to $1.72 \mathrm{~g}$ for middle schools. Based on the Welch F-test, the test for equality of means, these differences in effective fiber per serving by school were statistically significant $(P=0.0045)$.

\section{Discussion}

The NSLP, upon implementation of revised nutrition standards via HHFKA, provides school children with greater access to healthy menu items such as fruits, vegetables, and whole grains. However, food waste is a fact of life in the NSLP. There are many reasons for plate waste, including dislike of the foods served, the composition of meals, the environment in which students are eating, the lack of time to eat, and the influence of peers. On the other hand, certain fruits and vegetables may serve as gateway foods to promote food consumption, in part likely due to their popularity. Ishdorj, et al. reported on the impact of specific vegetable/entrée pairings on school plate waste [6]. Other studies have examined plate waste after the implementation of the new standards. Bykeret, al. collected food waste data from one pre-kindergarten and five kindergarten classes from one elementary school for one full week in March 2013 [7]. 45.3\% of all food that was served was wasted with vegetables being wasted the most (51.4\%) followed by the main entrée (51.0\%).
Cohen and co-workers measured plate waste in four schools (grades 3-8), with two data collection days per school in an urban low-income district (approx. 85\% F, R/P), collecting pre- and post- implementation [8]. $24.9 \%$ of vegetables and $72.3 \%$ of entrées were consumed pre-, and $41.1 \%$ of vegetables and $87.9 \%$ of entrées were consumed post. Schwartz, et al. collected data from 12 middle schools (5th to 7th grade) located in an urban, low-income district ( $>70 \%$ Free, $13 \% \mathrm{R} / \mathrm{P}$ ) [9]. The percentage of vegetable servings consumed increased from $45 \%$ to $64 \%$. The consumption of entrées increased from $71 \%$ to $84 \%$. The investigators concluded that the revised NSLP nutrition standards and policies led to more nutritious meals and less overall plate waste. The percentage of vegetable servings consumed increased from $45 \%$ to $64 \%$. The consumption of entrées increased from $71 \%$ to $84 \%$. The investigators concluded that the revised NSLP nutrition standards and policies led to more nutritious meals and less overall plate waste. Capps, et al. reported that after USDA issued the more stringent school meal nutrition standards, vegetable PW in six elementary schools from two Texas ISDs was significantly higher relative to the period before these new standards were instituted [11].

In the present study we examined the consumption of selected fruits, vegetables, and entrées at two school levels (elementary and middle) in one ISD in Texas when grapes were present on the menu ("grape days") and when they were not. The endpoints of our analysis included lost dollars and lost nutrients (calories, fat, sodium, protein, and fiber). These specific nutrients were analyzed because the participating schools provided food composition data for them with respect to the foods on the menu during our study. As well, each one of these nutrients is critical in the diet of schoolchildren. Whereas protein and fiber enjoy a more positive nutrition reputation than do fat and sodium due to restrictions required for the latter, it cannot be ignored that along with protein, fiber, and other essential nutrients, fat and sodium are important contributors to diet quality and health when consumed in proper amounts, when care is exercised to not over consume them. The amount of calories in NSLP lunches are designed on average to provide roughly one-third of a child's daily requirement. So in order to achieve this recommendation, ideally there should be no waste.

Regarding calories consumed on grape days, the school children were consuming more food and associated calories compared to non-grape days. The reasons for this situation are not immediately obvious, however. One might speculate that the popularity of the grapes positively impacted the children's entrée and vegetable eating behaviors, resulting in less plate waste.

We observed that neither grapes nor other fruit contributed directly to fat consumption, as fruit is naturally low in fat. However, the fat consumption coming from the entrées, vegetables and fruits collected showed similar patterns on grape days versus non-grape days. For instance, the entrées that were wasted the least or consumed the most tended to be cheese enchiladas, chicken nuggets, chili cheese hot dogs, and breaded chicken 
sandwiches, while cheesy potatoes, BBQ on bun, and hamburgers were wasted the most or consumed the least. There was a lack of a significant effect of grape days versus non-grape days on entrée waste/consumption as related to fat. There was however a school level effect for fat. Since the effective fat per serving from entrées, vegetables, and fruits was significantly lower for elementary schools (grades $\mathrm{K}-5$ ) in comparison to middle schools (grades 6-8), the younger children wasted more fat.

The effective sodium depended largely upon the entrée component of the meal, and to a lesser extent, the vegetable. We detected a school level effect. The entrées, as compared to the fruit or the vegetable components, contained the majority of the sodium. This result was not unexpected - as many of the popular entrees are typically processed and seasoned with salt. The fact that the elementary school children were consuming less sodium is possibly related to the fact that they ate smaller amounts of the meal entrée. There was a lack of a significant effect of grape days versus non-grape days on entrée waste/consumption as related to sodium.

Food waste is a challenging issue at multiple societal levels that has potentially far-reaching in consequences in terms of nutrition, economics, and the environment. Wasted food is indeed a wasted opportunity in terms of lost nutrients and nourishment as well as wasted dollars spent by school foodservice. However, even before any food is made available to school children, there are a variety of costly resources (water, energy, food production, transportation, and food service workers) to be considered [10]. If food is wasted at the point of consumption, these costs are lost as well. In addition, there are costs associated with the collection and disposal of food that is wasted, which may negatively impact the environment. These considerations point to the importance of understanding the nature of food waste, and the need to develop strategies to minimize it.

Concerning demographic data, there was greater demographic homogeneity with the two middle schools than with the two elementary schools in terms of student enrollment as well as $\%$ F/RP lunches. Although not matched demographically, the differences suggest a socio-economic diversity, particularly at the elementary school level. The significance of higher percentages of F/RP school children is that these schools are more socioeconomically challenged, and likely to rely more on school meals rather than other meals for daily sustenance. All else equal, it would be reasonable to postulate that plate waste should be lowest at the school with the highest \%F/RP (E1) compared to the school with the lowest \%F/RP (E2).

It might seem obvious to many foodservice employees that grapes are a popular fruit item with school children. In our study, sample evidence exists to confirm that when offered as a fruit choice, grapes were favored over the other fruits and also were minimally wasted compared to other fruits. The schools served both the green (Thompsons) and the red seedless varieties (Emperor and Red Globe), depending upon availability. While we lack specific data on the color issue, anecdotally we did not observe that color had an impact on wastage. The manner of service was standard and consistent, with typically fourteen grapes offered per tray, and the red and green were not mixed.

Inadequate vegetable intake has been highlighted as a serious concern among all age groups, including school-age children [12]. In considering the possibility that grapes might serve as a gateway food to healthier eating, it would be important to show enhanced consumption of vegetables as an under-consumed group, on grape days, for example. In addition, one could consider the impact of grapes on the intake of calories, protein, fat, and key shortfall nutrients (calcium, potassium, vitamin D, and fiber). Regarding increasing vegetable intake, when we looked at plate waste when grapes were offered, vegetable plate waste was calculated at $\$ 0.0266$ per serving on average, compared to $\$ 0.0351$ when grapes were not offered. This significant difference supports the suggestion that grapes may serve as a gateway to healthier eating.

Grape consumption, in addition to its indirect positive impact on nutrition due to decreasing plate waste and increasing consumption, directly enhances the nutritional intake of school children through its own inherent nutrients. These include not only vitamins and minerals but also phytochemicals, which function as antioxidants. Codoner-Franch, et al. has attested to the fact that increasing the antioxidant capacity of the diet through specific fruit consumption can combat oxidative stress and the resulting degenerative diseases [13]. Grapes are a source of polyphenolic antioxidant compounds, and these have been shown to lessen cardiovascular disease risk [14].

This research had several limitations. In our study, only two elementary schools and two middle schools in Texas participated, representing one ISD. Therefore, the results may not apply to other parts of the state, or other regions of the country. The schools had total control over the menus and foods served as well as any competitive foods served. Regarding our methods used to evaluate food waste, it was not possible to estimate whole fruit waste of apples, oranges and bananas, since these fruits would have to be collected individually. In addition, these fruits have cores and peels that made plate waste estimates problematic within our manpower and budget limitations. Instead, we collected grapes and canned fruits such as pineapples, oranges, peaches, and apple sauce that were offered in trays. The type of processing can influence sensory (flavor, color, texture) as well as mechanical properties. However, even though the grapes were fresh not canned, from a nutritional perspective, it is known that all forms of fruits and vegetables - fresh, frozen, canned, dried, and $100 \%$ juice - provide important nutrients and phytochemicals. Canned and frozen fruits and vegetables are typically packed quickly upon harvest, which preserves their peak flavor and nutritional value.

Further, it bears repeating that we did not analyze the entire meal, but instead focused on grapes, other fruit, entrées, and vegetables. For instance, dessert items and beverages were not part of our evaluation. These meal components obviously also 
contribute to calories and nutrients, as potentially consumed or wasted. Therefore, these meal components would need to be taken into account if analysts were to attempt to quantify the entire calorie and nutrient content of consumed versus wasted food.

Although not quantified in this study, purchases of competitive foods prior to lunch may have reduced hunger leading to decreased consumption of vegetables by older children. Competitive foods and Foods of Minimal Nutritional Value (FMNV) are at odds with healthy school nutrition policies. In addition, since we investigated the effect of the new standards immediately following implementation, we could only observe the initial student response to the change. It would be desirable to monitor plate waste six months, a year, and longer postimplementation to allow for children to adjust to vegetable offerings and become more accustomed to the changes.

Regardless of well-intended legislation, regulation and government programs that try to remedy low intake of vegetables by offering greater variety, children eat the vegetables they like and throw away the rest. Whether or not school children can be taught/instructed to consume greater vegetable variety is another issue altogether, it is within the realm of targeted health and nutrition education messages to school children to encourage changes in vegetable consumption behavior.

\section{Acknowledgement}

The authors acknowledge the California Table Grape Commission for providing funding for this research. The authors would like to thank Asha Girimaji, research assistants and school food service directors and personnel for their assistance with providing cost, nutrient, and associated data collection. All authors have read and approved the final manuscript.

\section{Declarations}

\section{Conflict of Interest: NA}

Ethical Approval: This study was approved as exempt by the Institutional Review Board (IRB) at Texas A\&M University, IRB study \# IRB2014-0647.

\section{Clinical Trial Registration: NA}

\section{References}

1. Brewer D, Hershberger S, Gaetke L. Healthy hunger-free kids act increases phytochemicals in menus and curriculum furthers identification of phytochemical-rich foods. J Nutrit Health Food Sci. 2016;4(1):1-6. Doi: 10.15226/jnhfs.2015.00156

2. Drewnowski A, Rehm CD. Vegetable cost metrics show that potatoes and beans provide most nutrients per penny. PLOS One. 2013;8(5):17. Doi: $10.1371 /$ journal.pone.0063277
3. McGill CR, Keast DR, Painter JE, Romano CS, Wightman JD. Improved diet quality and increased nutrient intakes associated with grape product consumption by U.S. children and adults: national health and nutrition examination survey 2003 to 2008. J Food Sci. 2013;78(6):A1A4. Doi: 10.1111/1750-3841.12066

4. Chu YL, Warren CA, Sceets CE, Murano PS, Marquart L, Reicks M. Acceptance of two US Department of Agriculture commodity wholegrain products: a school-based study in Texas and Minnesota. J Am Diet Assoc. 2011;111(9):1380-1384. Doi: 10.1016/j.jada.2011.06.003

5. United States Department of Agriculture Food and Nutrition Service. National School Lunch Program and School Breakfast Program: nutrition standards for all foods sold in school as required by the Healthy, Hunger-Free Kids Act of 2010. Interim final rule. Federal Register 78: 39067-120. 2013.

6. Ishdorj A, Capps O Jr, Storey M, Murano PS. Investigating the relationship between food pairings and plate waste from elementary school lunches. Food Nutr Sci. 2015;6(11):1029-1044. Doi: 10.4236/ fns.2015.611107

7. Byker CJ, Farris AR, Marcenelle M, Davis GC, Serrano EL. Food waste in a school nutrition program after implementation of new lunch program guidelines. J Nutr Educ Behav. 2014;46(5):406-411. Doi: 10.1016/j.jneb.2014.03.009

8. Cohen JF, Richardson S, Parker E, Catalano PJ, Rimm EB. Impact of the new U.S. Department of Agriculture school meal standards on food selection, consumption, and waste. Am J Prev Med. 2014;46(4):388394. Doi: 10.1016/j.amepre.2013.11.013

9. Schwartz MB, Henderson KE, Read M, Danna N, Ickovics JR. New school meal regulations increase fruit consumption and do not increase total plate waste. Child Obes. 2015;11(3):242-247. Doi: 10.1089/ chi.2015.0019

10. Pimentel D, Hall CW. Food and Energy Resources.1st ed. Academic Press, Orlando (FL); 1984.

11. Capps Jr O, Ishdorj A, Murano PS, Storey M. Examining vegetable plate waste in elementary schools by diversity and grade. Health Behav Policy Rev. 2016;3(5):419-428. Doi: 10.14485/HBPR.3.5.2

12. Dietary Guidelines Advisory Committee. Scientific Report of the 2015 Dietary Guidelines Advisory Committee,Part D, Chapter 1: Food and Nutrient Intakes, and Health: Current Status and Trends. Office of Disease Prevention and Health Promotion, United States Department of Health and Human Services; 2016.

13. Codoner-Franch P, López-Jaén AB, Muñiz P, Sentandreu E, Bellés VV. Mandarin juice improves the antioxidant status of hypercholesterolemic children. J Pediatr Gastroenterol Nutr. 2008;47(3):349-355. Doi: 10.1097/MPG.0b013e31816a8cdb

14. Blumberg JB, Vita JA, Chen CY. Concord grape juice polyphenols and cardiovascular risk factors: dose-response relationships. Nutrients. 2015;7(12):10032-10052. Doi: 10.3390/nu7125519 